Now if we write instead of the above-

$$
w=\frac{k}{d l} \sqrt{\frac{T}{s}},
$$

where $k$ is some constant, it is evident that $k$ will not depend on the nature of the string but solely on the system of units employed to express $d, l$, and $T$.

If C.G.S. units be employed, we have, as stated in Prof. Everett's translation of Deschanel-

$$
n=\frac{1}{2 l} \sqrt{\frac{T}{m}}
$$

where $m$ is the mass of unit length ; and as we may write instead of $m, \pi r^{2} s, r$ being the radius of the wire, we shall have-

$$
n=\frac{\mathrm{I}}{\sqrt{\pi}} \cdot \frac{\mathrm{I}}{2 r l} \cdot \sqrt{\frac{T}{s}}, \text { or } \frac{\mathrm{I}}{\sqrt{\pi}} \cdot \frac{\mathrm{I}}{d l} \cdot \sqrt{\frac{T}{s}},
$$

so that here $k=\frac{\mathbf{r}}{\sqrt{\pi}}=\cdot 5642$ approximately.

With any other system of units we may of course determine $k$ from the value just given, by multiplying or dividing by the ratios of the new to the C.G.S. units; for example, if $d$ be expressed in millimetres, $l$ in metres, and $T$ in kilogrammes, our new constant would be-

$$
\begin{gathered}
k=\frac{\mathrm{I}}{\sqrt{\pi}} \cdot \frac{\text { IO }}{\mathrm{I}} \cdot \frac{\mathrm{I}}{100} \cdot \sqrt{981000} \\
=\frac{99.04}{\sqrt{\pi}}=55.87 .
\end{gathered}
$$

But we may also determine $k$ directly for any system of units in the following manner:-If, in the formula-

$$
n=\frac{k}{d l} \wedge \sqrt{\frac{T}{s}},
$$

we make $d, l, T, s$, each unity, we shall have-

$$
n=k \text {. }
$$

Imagine then a wire of water, I mm. diam., I wetre long, stretched by a weight of I kilo.: its weight would be 7854 grm., and $H$, the "tension length," or length which would be equal in weight to the stretching weight, would be $\frac{1000}{7854}$ $=1273.2$ metres. The velocity $v$ of transmission of a pulse along the wire would be $\sqrt{g H}=\sqrt{9.81 \times 1273^{\circ}}=111.76$ metres per second, and the number of vibrations per second-

$$
n=\frac{v}{2 l}=\frac{\text { IrI:76 }}{2}=55 \cdot 88=k,
$$

the same figure as that obtained above.

If the units in which $d, l$, and $T$ are expressed are respectively the tenth of an inch, the foot, and the pound, $k$ becomes 48.66 .

In the later editions of Ganot's "Physics" we find the formula-

$$
n=9.8257 \sqrt{\frac{c}{l}}
$$

given, where $c$ is the "tension length," and $l$ the length of the string, both expressed in inches. This formula would of course be of more easy application than those given above when we know the weight per foot of the string, but does not directly show the relation of $n$ to the diameter and specific gravity.

Newcastle-on-Tyne W. J. GREY

\section{The U.S. Weather Charts}

I SHOULD be much obliged if you would inform me whether the United States Monthly Charts of Meteorological Data, in continuation of the series published in NATURE, can be procured in London, and if so where.

6, Charles Street, Grosvenor Square, December 7

\section{Climate of Vancouver Island}

Mr. ALFRED R. WALLACE asserts in his letter jublished in NATURE, vol. xxiii. p. 124, that the climate of Vancouver Island is not so mild as that of London.

For three yenrs I commanded a gunboat on those shores; sfeaking from recollection, and not from recorded observations, and with great deference to so distinguished a naturalist as $\mathrm{Mr}$.
Wallace, I should have said that the climate of Vancouver Island was a good deal milder than that of London.

Travellers' Club, Pall Mall, S.W., December I I

EDMUND H. VERNEY

\section{Meteors}

ON the evening of November 20 at about $8 \mathrm{p} . \mathrm{m}$. my attention was attracted by a number of meteors appearing as often as once per minute in different quarters of the heavens, but pursuing courses apparently radiating from a point near the constellation Andromeda.

Lyons, New York, November 22 M. A. VEEDER

\section{THE PROBABILITY OF PHYLLOXERA CROSSING THE TROPICS}

$\mathrm{MUCH}$ alarm has been felt by the wine-growers of South Africa at the possibility of the phylloxera being introduced into the Cape vineyards. Very stringent regulations have been framed in consequence, prohibiting the importation of living plants or vegetables in any form ; and so rigidly have these regulations been carried out that it is stated that, in accordance with them, a cargo of potatoes from New Zealand was destroyed on its reaching Capetown.

It is generally conceded by the experts who have been consulted that the importation of vines, on the tissues of which the phylloxera would be able to live in transit, must be prohibited. The phylloxera can however, it is admitted, feed on no other plant but the vine, and the important question for the South African Government to decide is whether it is really needful to exclude other plants or vegetables besides the vine. In order to obtain the best opinion upon this point, Dr. Maxime Cornu was consulted. He accordingly drew up several reports, in which he expresses the opinion that, though extremely unlikely, it is still theoretically possible that the phylloxera should be conveyed from Europe to South Africa by means of other vegetable products than the vine, and he therefore supports the prohibitive action taken by the Cape Government.

The inconvenience to the community which such a policy involves is necessarily considerable. 'The grounds of Dr. Maxime Cornu's decision have therefore been carefully considered by an entomologist who has studied the subject and who has drawn up the following notes The question is of great importance to all wine-growing countries in the southern hemisphere, and as these doubtless contain many readers of NATURE, I think the publication of these notes in its columns will give them the best opportunity of being fairly considered.

W. T. T. D.

Notes on Dr. Cornu's Reports on the Phylloxera, and on the Protective Measures against its Introduction.

Among the "truths" laid down in the first report, No. I. is, "The Phylloxera vastatrix lives only upon the vine." This is emphasised in the third report ("Memorandum on Laws of Protection, \&c." ), Paragraph No. IV., stating, "they (the insects) can, moreover, subsist only upon the vine."

Notwithstanding these unreserved statements of this fundamental fact in the life history of phylloxera, the same "Memorandum on Laws of Protection, \&c.," proceeds (in its "General Conclusion ") to recommend, "if such a course were possible," the imitation of "the example set by Algeria, and to forbid the introduction of all vegetable products whatever, with the exception of those which are absolutely required for consumption."

It may well be asked on what ground such a recommendation is based. After stating (Third Report, Paragraph IV.) that the phylloxera cannot live when dissociated from the vine for more than four or five days, and requircs protection from dessication in any case, Dr. 